\title{
Investigation of the negative influence of cooling lubricants on the deformation of the machine tool structure
}

\author{
Christian Brecher ${ }^{1}$, Filippos Tzanetos ${ }^{2}$ and Daniel Zontar ${ }^{2}$ \\ ${ }^{1}$ Machine Tool Laboratory of the RWTH Aachen (WZL), Steinbachstr. 15, 52072 Aachen, Germany \\ ${ }^{2}$ Fraunhofer Institute of Production Technology (IPT), Steinbachstr. 17, 52072 Aachen, Germany
}

\begin{abstract}
Cooling lubricants have a significant influence on the thermal state of a machine tool. The fluid absorbs the thermal energy of the cutting process and dissipates it to prevent wear of the tool and distortion of the work piece. However, the unpredictable flow of the cooling lubricant also transfers the energy to the machine tool structure and can thus have a negative impact on the produced work piece quality. While the thermal behaviour of machine tools under the influence of thermal environmental conditions is already the subject of ongoing research projects, the influence of cooling lubricants on the thermal state of the machine tool and thus the achievable manufacturing accuracy is still largely unexplored. This paper investigates the thermally induced deformations of the machine tool structure, as well as the impact on the Tool Centre Point (TCP).
\end{abstract}

\section{Introduction}

According to Mayr et al. [1], the machine tool users have realized that "comparable machine tools can show significantly different thermal errors and that in some machine tools most of the energy supplied to the machine tool is used to stabilize the temperatures". This means that the task to ensure that the machine tools are performing to their quoted accuracy specifications is now of paramount importance, although still highly complex. Due to the increased awareness of the industry, both machine tool users and manufacturers carry out such assessment measurements. This has led to a rapid development of new measurement techniques that are faster, more automated, easier, cheaper and more precise. However, most of the currently available correction methods don't consider the influence of cooling lubricant due to its stochastic nature. Hence, this research attempts to investigate the following three research questions: 1) Are the temperature and the deformation fields of the machine structure greater in magnitude and more inhomogeneous when using cooling lubricant? 2) How long does it take to reach a stationary state of deformation in the machine frame when using cooling lubricants? 3) How large is the influence of the cooling lubricant on the deformation of the machine frame and how large on the displacement of the TCP?

\section{Theoretical Background}

\subsection{State-of-Research concerning the influence of cooling lubricants}

A first analysis of all thermal sources on a machine tool were give first in [2], where the effects of not only the internal heat sources were investigated but also those of environmental temperature and the cooling lubricant. A correlation analysis between the dislocation in X-, Y- and $\mathrm{Z}$-direction and the structural temperatures as well as the cooling lubricant temperature and the environmental temperature led to the following conclusion: The influence of cooling lubricant gets less and less significant with respect to environmental influences for machine tool components further from the working volume, which is the expected behaviour. It has also been found that the temperature of the machine frame increases considerably with cooling lubricant, since the heat of the process is absorbed by the coolant and spread to the frame through the stream of the coolant. The temperature distribution over the machine frame also becomes more inhomogeneous spatially, since the coolant is thrown in many directions and can cause more local effects. The resulting deformation has been found to be too complex to be determined only from temperature measurements according to [3] and [4]. The duration until steady state in the machine frame's temperature was observed to be significantly extended with cooling lubricant in [3] and [4], since the coolant initiates an additional heat transfer mechanism. It has also been proven that these negative effects on the thermal stability of the machine structure can be minimized by controlling the cooling lubricant temperature and by compensation through the $\mathrm{CNC}$ in [5]. Until now, it is still no common practice to control the cooling lubricant temperature, since the negative effects are not expected to exceed a few microns. 


\subsection{Integral deformation sensors for thermal errors}

A suitable solution can be based on the integral deformation sensors (IDS), which measure the cumulative effect of all thermal sources, including environmental and cooling lubricant influences. The development of the IDS is described in detail in [6] and [7]. The sensors are integrated in machine tool components, so they measure the thermally induced deformation of each component. Since the mechanical constraints of each machine tool component are predefined, the integral deformation sensors amend enough information to estimate the overall deformation. For example, a block with a fixed and a loose bearing on both ends of its lengthiest dimension (e.g. spindle carrier) will deform in a unique way than a block that has one fixed and one free side in one of its dimensions (e.g. column or machine frame). Considering the expected temperature gradients, it is thus possible to derive expected error component shapes. Then, the proper positioning of the IDS is established by the amount of information needed to quantify these shapes, as well as the scalar (positionindependent) error components. The amount of integral deformation sensors ranges from one to three sensors per machine tool component, since every such sensor offers one-dimensional information, but their combinations can help to estimate several error components, depending on the configuration (sensors integrated in parallel to each other or including inclined sensors, sensors integrated in different lengths along the machine tool component).
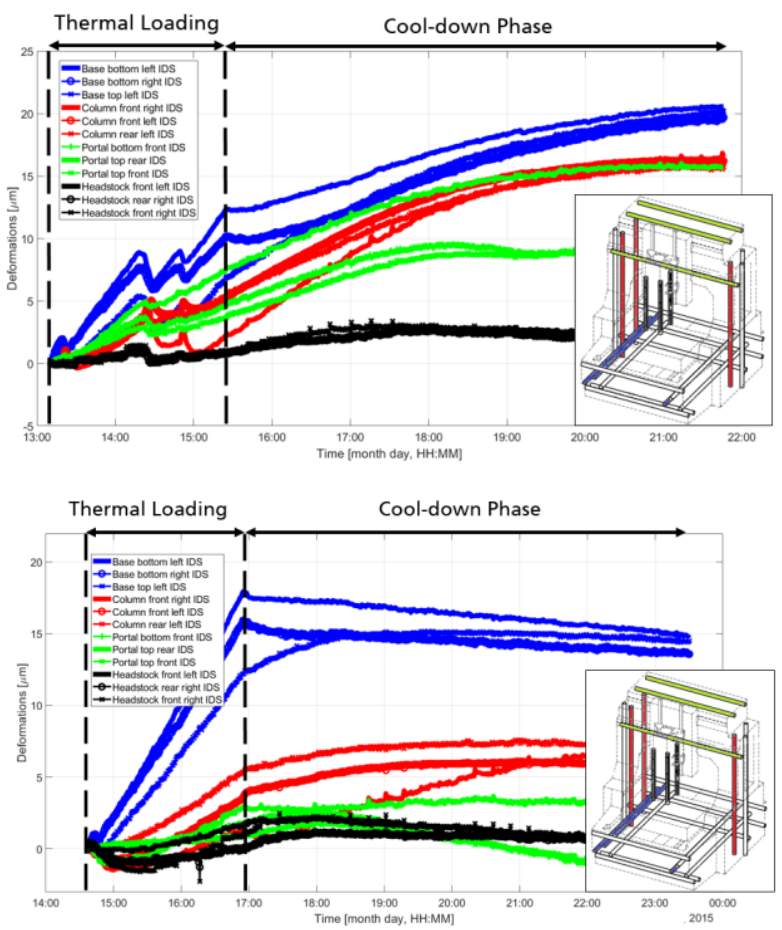

Figure 1. Deformations of machine tool structure due to $\mathrm{Y}$-axis loading with respect to a zero thermal state at the beginning of the experiment; top: without cooling lubricant; bottom: with cooling lubricant

\section{Experimental procedure}

Experimental investigations were carried out on a middle-sized machining centre in duoblock-construction. For the measurement of the TCP dislocation, four reference balls were mounted on the working table in different positions across the entire working space. This measurement was repeated approximately every fifteen minutes with two measurements taken at each reference ball. The uncertainty of the wireless probe measurement is $3.2 \mu \mathrm{m}$ as calculated in [8]. To investigate the thermal behaviour of the machine tool structure, measurements have been obtained from a thermo-symmetric 3-axis machining centre with the work piece fixed on the y-slide. Three integral deformation sensors are used to detect the thermal state of each component (machine base, column, portal beam, spindle carrier), except from the cross-slide and the work piece table. In overall, nine such sensors are used for the entire machine, as well as twenty-seven temperature sensors. The IDS and temperature sensors were recorded continuously with a sample rate of $2 \mathrm{~Hz}$.
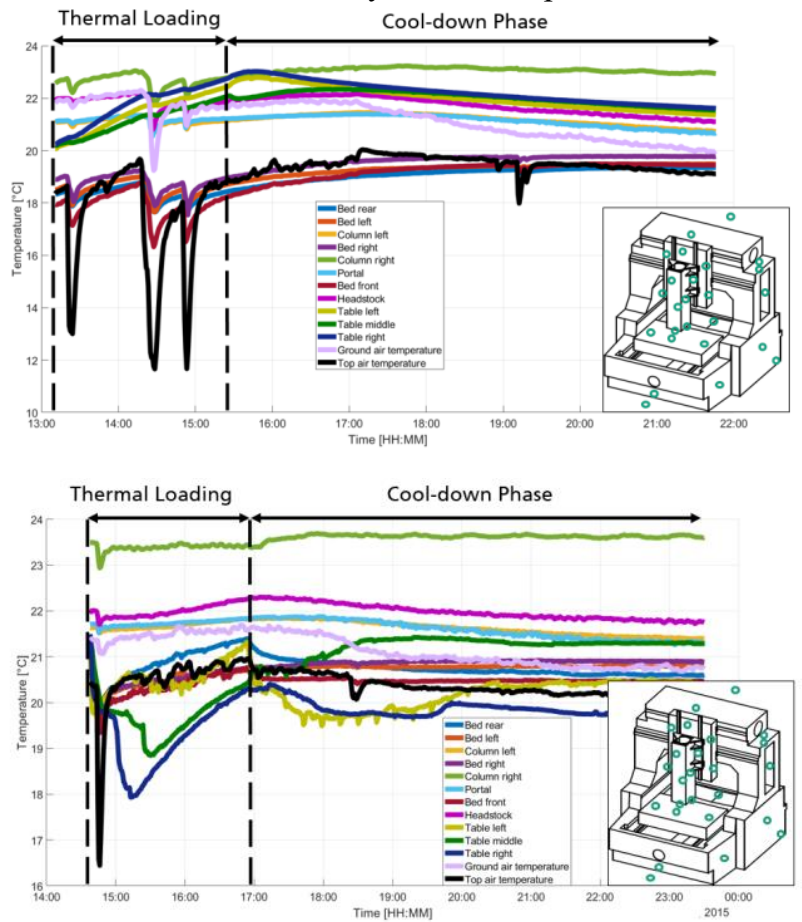

Figure 2. Temperatures of machine tool structure due to $\mathrm{Y}$-axis loading; top: without cooling lubricant; bottom: with cooling lubricant

The uncertainty of the temperature sensors is $\pm(0.3+0.005 \cdot \mathrm{T}) \quad{ }^{\circ} \mathrm{C}$ for class $\mathrm{B}$ type Pt100. The uncertainty of the measurement with the IDS is $1 \mu \mathrm{m} / \mathrm{m}$. The column IDS are $6.5 \mathrm{~m}$ long, the machine bed IDS are $2.2 \mathrm{~m}$ long, the portal IDS are $3.2 \mathrm{~m}$ long and the spindle stock IDS are $1 \mathrm{~m}$ long. Hence, the highest measurement uncertainty is $6.5 \mu \mathrm{m}$ for the column IDS. In order to introduce thermal loads, the work piece table in the $\mathrm{Y}$ axis was set to execute a repeated motion with $100 \%$ feed rate $(80 \mathrm{~m} / \mathrm{min})$ for approximately two hours. The machine enters then standby to cool down, while the control is still active. All measurements continue for an additional six hours during the cool-down phase. For comparison purposes, a similar measurement procedure is followed, were the cooling lubricant is activated during 
the phase of thermal loading and de-activated again during cool-down. In order to ensure that the machine tool has reached a stationary state thermally before the start of the measurements, it is kept at a standstill for 24 hours with the control system switched on.

\section{Experimental Results}

It was found that the machine frame experiences deformations up to $12 \mu \mathrm{m}$ due to loading through movement of the work piece table in Y-axis without cooling lubricant (Fig. 1 left). However, the influence of environmental temperature seems to be more detrimental, especially due to the fact that the hall door was opened three times during the experiment (Fig. 2 left). When noticing the relative deformations with respect to a zero thermal state defined at the beginning of the experiment (Fig. 1 left), it is evident that the machine frame continues to expand after the thermal loading is stopped. The three IDS mounted on the machine bed seem to grow in different rates during loading, which means that bending appears and then slowly come back together to the same amount of growth, which can be interpreted as pure expansion. This means that the work piece table movement is responsible mainly for bending and that the pure expansion is mainly inflicted by the fluctuation of the environmental temperature from day to night. This cycle becomes more obvious when noticing the relative deformations with respect to a zero thermal state at midnight before the experiment (Fig. 3).

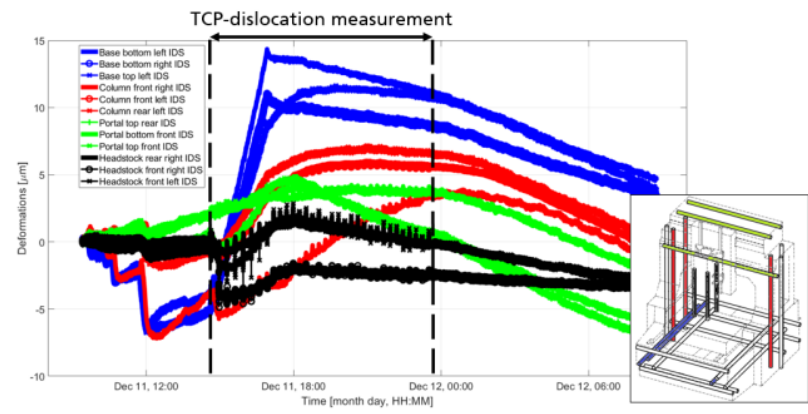

Figure 3. Deformations of machine tool structure due to Y-axis loading with cooling lubricant with respect to a zero thermal state before the experiment

On the other hand, the same loading but with cooling lubricant leads to deformation up to $18 \mu \mathrm{m}$ (Fig. 1 right), which is not a significant difference, considering that the first experiment was also influenced by sudden environmental temperature changes. However, it is still evident that this time the machine bed expands more than the other machine tool components, since it is influenced directly by the cooling lubricant, while the column, portal beam and headstock are isolated from it and influenced more from the environmental temperature. As in the previous experiment, the three IDS on machine bed grow with different rates during loading, which leads to bending and then slowly go back together to a uniform expansion during the cool-down phase. The difference of the remaining deformation in Fig. 1 left in comparison to the one in Fig. 1 right is characteristic of the detrimental effect of environmental temperature. Depending on the environmental conditions of the day, a machine tool can have a different thermal state, which means that sometimes it may expand and sometimes contract in spite of similar production conditions. The influence of cooling lubricant is also apparent at the significant change of the work piece table temperature (Fig. 2 right). Since the cooling lubricant runs to the rear towards the tank, the bed temperature changes significantly only on the rear, while its temperature on the front and the sides remains more or less constant. This creates a temperature differential in the $\mathrm{Y}$-direction, which in turn leads to the increased observed expansion during loading. During this experiment, the hall door was opened only once, in contrast to the first experiment (Fig. 2 left). This environmental temperature cycle and its effect on the machine frame deformations is again apparent when noticing the relative deformations with respect to a zero thermal state at midnight before the experiment (Fig. 2 right). Finally, the TCP-dislocation seems similar from a steady-state point of view (Fig. 4): The maximum dislocation in Z-direction after 2 hours of loading without cooling lubricant is $60 \mu \mathrm{m}$, while it drops to $50 \mu \mathrm{m}$ with cooling lubricant. The dislocation in Y-direction drops from 30 to $25 \mu \mathrm{m}$, while the dislocation in X-direction is negligible due to the thermo-symmetric design of the machine. From a transient standpoint, it seems that the bed deformation becomes more critical faster, thus pivoting the dislocation in the positive $\mathrm{Y}$-direction faster. The spatial distribution of the TCP-dislocation also seems almost unchanged with cooling lubricant.
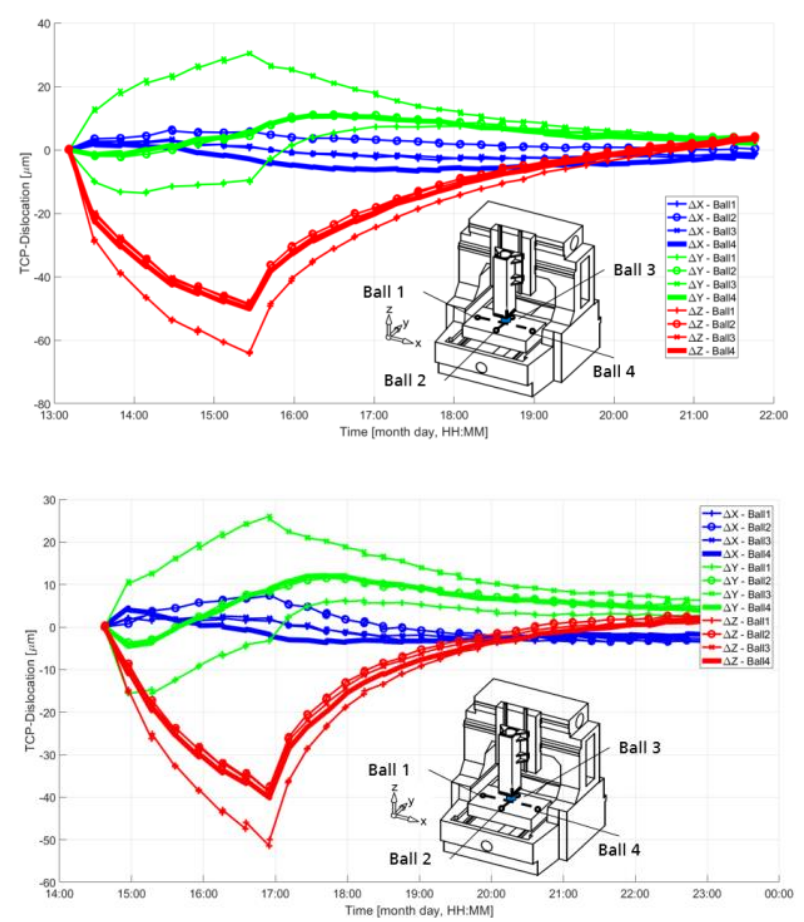

Figure 4. Dislocation of the Tool Centre Point (TCP) due to Yaxis loading; top: without cooling lubricant; bottom: with cooling lubricant 


\section{Equations and mathematics}

It was observed that the cooling lubricant leads to a greater expansion of the machine structure, but the TCPdislocation is affected negatively. The reason for this is the design of the machine tool, which uses the rear side of the machine bed for the cooling lubricant to flow back to its tank, while the work piece table is moving on the front side of the machine bed. This means that a good machine design can circumvent the negative effects of cooling lubricant on the machine structure, as they were observed in [2], [3] and [4]. It has been apparent in the investigations of this work that the environmental effects are much more detrimental than those of the cooling lubricant. However, the observed behaviour may vary strongly depending not on the volume of the cooling lubricant tank and the environmental temperature, since the tank itself is influenced significantly by fluctuations on the environmental temperature. The tank volume used in the experimental machine was 40 litres big, while the common practice is to use a tank of 120 litres, which means that the temperature of the cooling lubricant is more stable and less dependent on the environmental temperature. The transferability of the investigations is limited to machining centres (horizontal or vertical) in the following designs: a) cross-table and cross-bed construction; b) moving column construction; c) console bed construction similar to the machines investigated in [2] and [3]; d) portal construction with movable table. These designs can be found on most machining centres in conventional production. However, machines of portal construction with movable portal (Gantry type) and console column construction could have a different behaviour due to different kinematics between machine frame and machine tool components.

\section{Acknowledgements}

This work is funded by the DFG (German Research Foundation) within the framework of the trans-regional special research field CRC/TR96 "Thermo-energetic Design of Machine Tools" in subproject C03 "Structurally Integrated Sensors".

\section{References}

1. Mayr, J.; Jedrzejewski, J.; Uhlmann, E.; Donmez, M. A.; Knapp, W.; Härtig, F.; Wendt, K.; Toshimichi,
M.; Shore, P.; Schmitt, R.; Brecher, C.; Würz, T.; Wegener, K.: Thermal issues in machine tools. CIRP Annals - Manufacturing Technology (Vol. 61, Issue 2). Elsevier-Verlag, Amsterdam, (2012), pp. 771-791

2. Brecher, C.; Fey, M.; Wennemer, M.: The influence of coolant on the thermo-elastic machine tool behavior. In: Proceedings of the 16th euspen International Conference \& Exhibition. Nottingham, UK, (2016).

3. Mayr, J.; Gebhardt, M.; Massow, B. B.; Weikert, S.; Wegener, K.: Cutting fluid influence on thermal behavior of 5-axis machine tools. In: Procedia CIRP (Vol. 14). Amsterdam - Elsevier Verlag, (2014), S. 395-400

4. Mayr, J.; Egeter, M.; Weikert, S.; Wegener, K.: Thermal error compensation of rotary axes and mein spindles using cooling power as input parameter. In: Journal of Manufacturing Systems (Vol. 37). Amsterdam - Elsevier Verlag, (2015), S. 542-549

5. Brecher, C.; Jasper, D.; Wennemer, M.; Klatte, M.: Thermo Energetic Design of Machine Tools and Requirements for Smart Fluid Power Systems. In: Proceedings of the 10th International Fluid Power Conference (IFK). Dresden, (2016), S. 177-194

6. Brecher, C.; Klatte, M.; Wenzel, C.; Flore, J.: InProcess Machine Structure Deformation and Compensation of Resulting Workpiece Inaccuracies. In: Proceedings of the 10th International Conference on Laser Metrology, Machine Tool, CMM \& Robotic Performance (LAMDAMAP). Milton Keynes, USA: Shore Publishing, (2013), S. 111-121

7. Wenzel, C.; Klatte, M.: Structurally Integrated Sensors, In: Thermo-Energetic Design of Machine Tools (Vol.: Lecture Notes on Production Engineering - LNPE), Berlin: Springer Verlag, (2015), S. 209-221

8. C. Brecher, M. Klatte, F. Tzanetos: Analysis of spatial and temporal dependencies of the TCPdislocation measurement for the assessment of the thermos-elastic behavior of 3-axis machine tools, in: Proceedings of the 12th International Conference and Exhibition on Laser Metrology, Coordinate Measuring Machines and Machine Tool Performance (LAMDAMAP), Bristol, Gloucestershire, UK, (2017), pp. 122-132 